\title{
Perspectivas do uso da Robótica Educativa na Educação Infantil e no Ensino Fundamental
}

\author{
Anibal Lopes Guedes ${ }^{1}$, Fernanda Lopes Guedes ${ }^{2}$, Tatiana Brocardo Castro ${ }^{3}$ \\ ${ }^{1}$ Universidade Federal da Fronteira Sul (UFFS) \\ Erechim - RS - Brasil \\ ${ }^{2}$ Instituto Federal Sul-Rio-Grandense (IF-SUL) \\ Sapucaia do Sul - RS - Brasil \\ ${ }^{3}$ Instituto Educacional do Rio Grande do Sul (IERGS) \\ Porto Alegre - RS- Brasil \\ \{anibalguedes, fernandalguedes, tatianabrocardo\}@gmail.com
}

\begin{abstract}
The Educational Robotics allows articulate learning more playful, interactive, permeating even an improvement in the process school curriculum. Works the abstract concrete form, and thus stands as a new methodology of teaching and learning. Thus, this paper discusses and presents three educational initiatives that use robotics in elementary schools, located in western Santa Catarina and northern Rio Grande do Sul. For this, we used the Lego Mindstorms NXT robotic kit. As a result, it was found that the technology enables the integration, interaction, discussion and cooperation between students, teachers and employees, which somehow permeates one individual and collective development, providing opportunities for improvements in the educational processes and rethinking curriculum.
\end{abstract}

Resumo. A Robótica Educativa permite articular um ensino mais lúdico, interativo, permeando inclusive, uma melhoria no processo curricular da escola. Trabalha o abstrato de forma concreta, e, dessa forma, afirma-se como uma nova metodologia de ensino e aprendizagem. Sendo assim, este trabalho discute e apresenta 3 iniciativas pedagógicas que usam a robótica em escolas de Ensino Básico, situadas na região oeste de Santa Catarina e norte do Rio Grande do Sul. Para isso, usou-se o kit robótico Lego Mindstorms NXT. Como resultados, verificou-se que a tecnologia possibilita a inserção, interação, discussão e cooperação entre alunos, professores e colaboradores, o que, de certa forma, permeia um desenvolvimento individual e coletivo, oportunizando melhorias nos processos educativos e um repensar curricular.

\section{Introdução}

O computador não serve apenas para realizar tarefas humanas, como somar, processar e ensinar, mas pressupõe o desenvolvimento das capacidades cognitivas e meta-cognitivas 
de cada indivíduo, através de situações de aprendizagem que possibilitem uma melhor compreensão do mundo em que se vive (SANCHO, 2006).

A autora afirma que as tecnologias têm um enfoque transformador, uma vez que: alteram a estrutura de interesses de cada indivíduo; modificam a forma de pensar de cada indivíduo; alteram a natureza da comunidade. Corroborando com tal proposta, Correia (2013) afirma que as tecnologias devem promover o desenvolvimento de competências e habilidades cognitivas básicas de seus utilizadores, explorar a aprendizagem de uma forma interativa e lúdica, permitindo as pessoas novos processos educativos, novas experiências, novas descobertas e novas formas de aprender. Sendo assim, o robô é um meio atrativo que conforme Quintanilha (2008, p. 12), “convida professores e alunos a ensinar/aprender/descobrir/inventar em processos coletivos, capazes de conectar abstração e mundo concreto".

Por meio deles, é possível explorar a área da Robótica de forma educativa, vindo a somar esforços para transformar a vida escolar mais desafiadora, criativa e focalizada nos processos de ensino e aprendizagem.

No Brasil, projetos abordando a temática Robótica Educativa desenvolvem-se nos mais diversos segmentos, voltados na sua maioria, para o ensino médio e profissionalizante. Lopes (2010) afirma que há poucos projetos articulados com o ensino fundamental. Os autores afirmam que são poucas as instituições em nível fundamental que incluem conteúdos relacionados à educação tecnológica em seus currículos.

Frente ao que se apresenta, Trevisol, Cordeiro e Hass (2011) afirmam que as instituições de ensino são espaços de produção significativos para que iniciativas sociais e tecnológicas sejam realizadas, neste caso o estudo sobre Robótica na Educação, de forma a: Conhecer de perto a realidade social do público atendido de forma a modificála; Proporcionar a qualificação profissional do cidadão; Democratizar o acesso aos conhecimentos produzidos para a melhoria da qualidade de vida dos cidadãos; Fomentar a pesquisa científica; Promover a cidadania e valores democráticos aos diferentes atores sociais que se envolvem de forma direta e indireta nas ações.

Assim, a Robótica Educativa abre inexploradas potencialidades para a área da Educação e para o campo de pesquisa, transformando os cenários educacionais. Dessa forma, este artigo tem por objetivo apresentar considerações acerca de iniciativas desenvolvidas na área de Robótica Educativas aplicadas junto a alunos das series iniciais.

\section{Iniciativas empregando a Robótica Educativa}

Conforme os autores Bock, Furtado e Teixeira (2008) a escola representa uma das instituições sociais mais importantes, pois ela é o elo que media a interação entre o indivíduo e a sociedade, permitindo com que, a criança possa apropriar-se de valores e modelos sociais, repercutindo diretamente em sua autonomia.

Para tanto, a tecnologia representa parte deste elo, pois permite que sejam adotadas ações que viabilizem o processo educativo. Neste sentido, a Robótica Educativa nas escolas visa proporcionar aos alunos o despertar do raciocínio lógico, a criatividade, a autonomia no aprendizado, a compreensão de conceitos e procura 
melhorar a convivência em grupo, tratar a cooperação, o planejamento de atividades e tarefas (PIO; CASTRO; CASTRO JUNIOR, 2006).

Corroborando com Quintanilha (2008) a área de robótica educativa ainda é tímida e faltam profissionais com formação tanto em nível tecnológico quanto pedagógico. Porém, cabe, neste momento, mostrar iniciativas vivenciadas pelos pesquisadores em nível de ensino e de extensão. As propostas aqui sumarizadas são provenientes dos trabalhos de: Kerber (2009), Tosini e Holz (2010) e Zarpelon; Tortelli e Bieniek (2013). Em ambos os projetos utilizou-se como procedimentos metodológicos a observação direta da prática escolar e a intervenção em sala de aula.

A observação tem como vantagem identificar os fatos de forma direta, sem qualquer intermediação, como indica Gil (1994); trata-se de uma metodologia simples e sistemática. Dessa forma, a primeira etapa contou com a análise impactual das tecnologias, principalmente a Robótica no âmbito escolar.

Após a observação, a próxima etapa era o estudo do kit robótico Lego Mindstorms NXT, a fim de analisar e compreender seu uso, funcionamento e programação. Este kit foi escolhido tendo como base os quesitos elencados por Lopes (2010): conter uma quantidade de engrenagens significativa; permite a customização ou manufatura de suas peças; sua programação é simplificada pelo uso de blocos visuais programáveis.

Papert (1994) coloca que o ser humano aprende melhor quando está engajado na construção de algo que ele possa mostrar a outras pessoas e que seja significativo para ele. Estes ambientes computacionais, principalmente a Robótica, contribuem para essa forma de pensamento construcionista, porque os alunos se envolvem e interagem com o desenvolvimento de projetos.

Devido ao tempo, o estudo do kit Lego Mindsotrms NXT acabou concomitando com a etapa de observação das turmas nas escolas - apresentadas na sequência, onde a ideia é: a) investigar a prática docente, observando diretamente como as atividades são desenvolvidas, exploradas e sua relevância aos alunos; b) analisar a relação aluno e professor na sala de aula.

A partir da análise da realidade e do plano escolar de cada escola, passou-se para a experimentação de atividades em nível tecnológico. Para isso, utilizou-se o fluxograma proposto por Kerber (2009). A partir da estruturação experimental dos projetos, passou-se para a fase de intervenção na escola. O processo de intervenção tem como intuito viabilizar a "problematização coletiva junto às práticas de formação e potencializando a produção de um novo pensar/fazer educação.” (ROCHA, 2003).

A intervenção contou com o a formação dos professores e demais representantes legais das escolas, por meio de oficinas, para que estes possam conhecer o kit robótico e verificar possibilidades de utilização. Após isso, passou-se para a formação e validação do projeto com os alunos.

$\mathrm{Na}$ formação e validação dos projetos percebe-se que a Robótica Educativa, assegura um processo emancipador nos sujeitos. Isso se consegue a medida que novos estímulos e competências como a ludicidade, a criatividade e a interatividade são desenvolvidos. Moretto (2002) completa afirmando que o professor deve criar condições para que o aluno "aprenda a aprender", desenvolvendo situações de 
aprendizagens diferenciadas e estimulando a articulação entre saberes e competências. $O$ autor afirma que o professor é o responsável pela mediação da construção do processo de conceituação no aluno, mobilizando-o a utilizar recursos (cognitivos) para solucionar várias situações complexas.

Assim, percebe-se que o robô em sala de aula faça com que o aluno possa compreender melhor a situação a ser resolvida, fazendo-o buscar uma solução a esta situação e, na sequência, analisar os resultados obtidos.

\section{Conclusões}

Pelas análises obtidas com a tecnologia Lego Mindstorms NXT, os pesquisadores perceberam a vantagem do kit no aprendizado tanto de alunos quanto de professores, pois proporciona a criação de estruturas imaginativas concretas, envolvendo desde humanoides, réplicas de animais, veículos, entre outras.

Em contraponto a isso, percebe-se também, que o do kit robótico ainda é caro no Brasil, fato que possa ser um complicador, visto que, escolas públicas dependem de orçamentos estaduais e municipais.

Com o intuito de conhecer a realidade social do público atendido, visitaram-se as escolas atendidas, para verificar como são os alunos em sala de aula, quais atividades são desenvolvidas pelos professores, quais as principais dificuldades enfrentadas pelos alunos no seu processo de aprendizagem, se existem iniciativas na escola com o uso de tecnologias. Constatou-se que, faltam processos formativos que incentivem o uso do computador na escola, mais particularmente robôs, com os "pequenos".

Kerber (2009) destaca a necessidade de uma reformulação dos currículos escolares, uma formação de professores e representantes da escola, para que eles possam trabalhar adequadamente a interdisciplinaridade que a tecnologia possa proporcionar. A iniciativa também influenciou a relação entre o grupo, permitindo uma maior comunicação entre os alunos e professores, que de certa forma, era distante.

Já Tosini e Holz (2010), Zarpelon, Tortelli e Bieniek (2013) destacam o envolvimento da equipe (alunos e professores) no processo de experimentação. Além disso, indicam que a reformulação curricular e o processo formativo de professores, levantados por Kerber (2009), como sendo necessário e urgente na escola.

Ao serem questionados sobre como imaginavam um robô, para alguns, robô eram apenas aqueles com formas humanoides, outros nem tinham ideia do seria um robô. E quando questionados sobre as atividades propostas, os alunos gostariam que outras atividades fossem propostas Kerber (2009), Tosini e Holz (2010), Zarpelon, Tortelli e Bieniek (2013).

Diante disso, as instituições de ensino têm como papel principal a modificação da realidade apontada pelos pesquisadores, seja com a incorporação tecnológica da Robótica nos currículos do ensino fundamental, no processo formativo e emancipatório dos sujeitos e na qualificação profissional, a fim de criar uma sociedade mais justa e que promova o desenvolvimento dos indivíduos que dela fazem parte.

\footnotetext{
${ }^{1}$ Falas pessoais de professores consultados
} 


\section{Referências}

BOCK, A. M. B.; FURTADO, O.; TEIXEIRA, M. L. T. (2008). Psicologias: Uma introdução ao estudo da Psicologia. 14. ed. São Paulo: Saraiva.

CORREIA, S. (2008). Inteligência Emocional e Robótica na Educação. Revista Perspectiva. Disponível em: $<$ http://bica.imagina.pt/2008/inteligencia-emocional-erobotica-na-educacao/>. Acesso em: 07 abr. 2013.

GIL, A. C. (1994). Métodos e técnicas de pesquisa social. 4. ed. São Paulo: Atlas.

KERBER, F. M. (2009). Usando a Robótica como meio Educativo. Trabalho de Conclusão de Curso - Curso de Sistemas de Informação, Universidade do Oeste de Santa Catarina.

LOPES, D. Q. (2010). Brincando com robôs: desenhando problemas e inventando porquês. Santa Cruz do Sul: EDIUNISC.

MORETTO, V. (2002). Construtivismo, a produção do conhecimento em aula. 3 ed. Rio de Janeiro: DP\&A.

PAPERT, S. (1994). A máquina das crianças: repensando a escola na era da informática. Porto Alegre: Artes Médicas.

PIO, J. L. de S.; CASTRO,T. H. C.; CASTRO JUNIOR, A. N. (2006). A Robótica Móvel como instrumento de apoio à Aprendizagem de Computação. In: XVII Simpósio Brasileiro de Informática na Educação - SBIE, Brasília.

QUINTANILHA, L. (2008). Irresistível robô. Revista ARede, ed. 34, mar. Disponível em: $\quad<$ http://www.arede.inf.br/edicao-n-34-marco-2008/3920-irresistivel-robo>. Acesso em: 07 abr. 2013.

ROCHA, M. L.; AGUIAR, K. F. (2003). Pesquisa-intervenção e a produção de novas análises. Psic. cienc. prof., Brasília, v. 23, n. 4, dez.

SANCHO, J. M. (2006). De Tecnologias da Informação e Comunicação a Recursos Educativos. In: SANCHO, J. M. et. al. Tecnologias para transformar a Educação. Porto Alegre, RS: Artmed. p. 15-40.

TOSINI, J.; HOLZ, F. C. (2010). O emprego da tecnologia Bluetooth e robô Lego Mindstorms no Aprendizado de crianças. Trabalho de Conclusão de Curso - Curso de Sistemas de Informação, Universidade do Oeste de Santa Catarina.

TREVISOL, J. V.; CORDEIRO, M. H.; HASS, M. (Org.). (2011). Construindo agendas e definindo rumos. Chapecó, SC: UFFS.

ZARPELON, M. C.; TORTELLI, L.; BIENIEK, G. B. (2013). O uso da Robótica nos processos educativos de alunos da Educação Infantil e Ensino Fundamental. Projeto de Extensão, Universidade Federal da Fronteira Sul. 